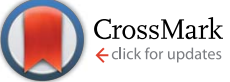

Cite this: RSC Adv., 2017, 7, 975

Received 16th October 2016 Accepted 21st November 2016

DOI: 10.1039/c6ra25319a

www.rsc.org/advances

\title{
A series of coordination polymers based on terphenyl tetracarboxylates and bis-pyridyl ligands with water vapor sorption properties $\dagger$
}

\begin{abstract}
Ling Li, Lei Lv and Ru-Dan Huang*
Six new coordination polymers, namely, $\left\{\left[\mathrm{Mn}_{2}(\mathrm{~L} 1)(\mathrm{bpfp})\left(\mathrm{H}_{2} \mathrm{O}\right)_{2}\right] \cdot 6 \mathrm{H}_{2} \mathrm{O} \cdot\left(\mathrm{CH}_{3} \mathrm{OH}\right)\right\}_{n}(1), \quad\left\{\left[\mathrm{Mn}_{4}\left(\mu_{3^{-}}\right.\right.\right.$ $\left.\left.\mathrm{O}_{2}(\mathrm{~L} 1)_{2}(\mathrm{bpe})_{2}\left(\mathrm{H}_{2} \mathrm{O}\right)_{2}\right] \cdot 2 \mathrm{H}_{2} \mathrm{O}\right\}_{n}(2)$, [Ni(HL1)(Hbpmp) $\left.\left(\mathrm{H}_{2} \mathrm{O}\right)_{2}\right]_{n}(3),\left[\mathrm{CO}_{2}\left(\mu_{2}-\mathrm{OH}\right)(\mathrm{HL} 1)(\mathrm{bpmp})\left(\mathrm{H}_{2} \mathrm{O}\right)_{4}\right]_{n}(4)$, $\left\{\left[\mathrm{CO}_{2}(\mathrm{~L} 2)(\mathrm{bpfp})\left(\mathrm{H}_{2} \mathrm{O}\right)_{2}\right] \cdot 4 \mathrm{H}_{2} \mathrm{O}\right\}_{n} \quad(5),\left\{\left[\mathrm{CO}_{2}(\mathrm{~L} 2)_{2}(\mathrm{bpe})_{2}\left(\mathrm{H}_{2} \mathrm{O}\right)_{2} \cdot 2 \mathrm{H}_{2} \mathrm{O}\right] \cdot\left(\mathrm{NH}_{4}\right)_{4}\right\}_{n} \quad$ (6) $\left(\mathrm{H}_{4} \mathrm{~L} 1=\left[1,1^{\prime}: 4^{\prime}, 1^{\prime \prime}-\right.\right.$ terphenyl]-2,2" ,5, 5" -tetracarboxylic acid, $\mathrm{H}_{4} \mathrm{~L} 2=\left[1,1^{\prime}: 4^{\prime}, 1^{\prime \prime}\right.$-terphenyl]-3,3",5,5" -tetracarboxylic acid, bpfp $=$ bis(4-pyridylformyl)piperazine, bpe $=1,2$-bis(pyridin-4-yl)ethane and bpmp $=N, N^{\prime}$-bis(4pyridyl)piperazine) were synthesized under hydrothermal conditions by terphenyl tetracarboxylates, bis-pyridyl ligands and transition metal salts. These six complexes were characterized by elemental analysis, infrared (IR) spectroscopy, thermogravimetric analysis (TGA), single-crystal X-ray diffraction, powder X-ray diffraction (PXRD) and fluorescence spectroscopy. Complexes 1 and 5 possess three-dimensional (3D) $(4,6)$-connected networks with $\left\{4^{3} \cdot 6^{3}\right\}_{2}\left\{4^{6} \cdot 6^{6} \cdot 8^{3}\right\}$ and $\left\{4^{4} \cdot 6^{10} \cdot 8\right\}$ $\left\{4^{4} \cdot 6^{2}\right\}$ topologies, respectively. Complexes 2-4 and 6 feature two-dimensional (2D) networks, which are expanded into 3D supramolecular frameworks via hydrogen bonding interactions. Desorption of lattice water molecules in complexes 1 and 2 was analyzed, and the values of water vapor uptake are $15.17 \mathrm{~mL} \mathrm{~g}^{-1}$ and $27.24 \mathrm{~mL} \mathrm{~g}^{-1}$, respectively.
\end{abstract}

\section{Introduction}

In recent years, the design and synthesis of hybrid metalorganic coordination polymers have attracted intense interest due to their various architectures, interesting topologies and desirable applications such as sorption, ${ }^{\mathbf{1 - 3}}$ separation, ${ }^{4}$ luminence, ${ }^{5,6}$ catalysis $^{7}$ and magnetism. ${ }^{8}$ To date, a large number of metal-organic coordination polymers with diverse structures have been synthesized., ${ }^{\mathbf{9} 10}$ In the process of synthesis, many factors influence the final structure, such as molar ratio of reactants, temperature, $\mathrm{pH}$ value, solvent system and auxiliary ligands, etc. ${ }^{11,12}$ Organic ligands, as one of the most important factors, are crucial to constructing novel architectures. ${ }^{\mathbf{1 3 , 1 4}}$ The O-donor polycarboxylate ligands are excellent organic ligands in forming various structures such as 0D cages, 1D chains, 2D grids and 3D frameworks. ${ }^{15}$ Among these, rigid tetracarboxylate ligands based on terphenyl moieties have been used to generate a large number of coordination polymers with remarkable

Key Laboratory of Cluster Science of Ministry of Education, School of Chemistry, Beijing Institute of Technology, Beijing 100081, PR China. E-mail: huangrudan1@ bit.edu.cn

$\dagger$ Electronic supplementary information (ESI) available: X-ray crystallographic cif files, check cif files, selected bond lengths and angles, PXRD curve, TGA curve, fluorescence spectra and additional figures for complexes 1-6. Complexes 1-6 have been assigned the following numbers: CCDC 1056874-1056879, respectively. CCDC 1056874-1056879. For ESI and crystallographic data in CIF or other electronic format see DOI: 10.1039/c6ra25319a properties. ${ }^{16}$ Additionally, N-donor ligands can offer nitrogen coordination donors to the metal centers, acting as hydrogen bond donors and acceptors. Therefore, N-donor ligands as auxiliary ligands are also wonderful candidates in producing novel coordination polymers. ${ }^{17}$

In this paper, we selected two types of rigid tetracarboxylate ligands based on terphenyl moieties $\left[1,1^{\prime}: 4^{\prime}, 1^{\prime \prime}\right.$-terphenyl]$2,2^{\prime \prime}, 5,5^{\prime \prime}$-tetracarboxylic acid $\left(\mathrm{H}_{4} \mathrm{~L} 1\right)$ and $\left[1,1^{\prime}: 4^{\prime}, 1^{\prime \prime}\right.$-terphenyl]$3,3^{\prime \prime}, 5,5^{\prime \prime}$-tetracarboxylic acid $\left(\mathrm{H}_{4} \mathrm{~L} 2\right)$ as the main ligands, three $\mathrm{N}$-donor ligands bis(4-pyridylformyl)piperazine (bpfp), 1,2-bis(pyridin-4-yl)ethane (bpe), and $N, N^{\prime}$-bis(4-pyridyl) piperazine (bpmp) as the auxiliary ligands, to react with different transition metal salts under hydrothermal conditions. Six complexes, $\left\{\left[\mathrm{Mn}_{2}(\mathrm{~L} 1)(\mathrm{bpfp})\left(\mathrm{H}_{2} \mathrm{O}\right)_{2}\right] \cdot 6 \mathrm{H}_{2} \mathrm{O} \cdot\left(\mathrm{CH}_{3} \mathrm{OH}\right)\right\}_{n} \quad$ (1),

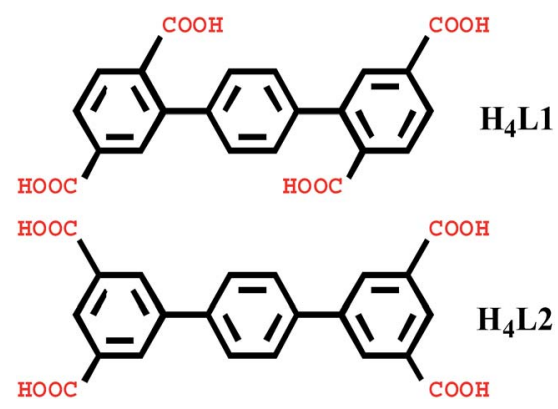

Scheme 1 Schematic structure of the organic linker $\mathrm{H}_{4} \mathrm{~L} 1$ and $\mathrm{H}_{4} \mathrm{~L} 2$. 
$\left\{\left[\mathrm{Mn}_{4}\left(\mu_{3}-\mathrm{O}\right)_{2}(\mathrm{~L} 1)_{2}(\mathrm{bpe})_{2}\left(\mathrm{H}_{2} \mathrm{O}\right)_{2}\right] \cdot 2 \mathrm{H}_{2} \mathrm{O}\right\}_{n} \quad(2), \quad[\mathrm{Ni}(\mathrm{HL} 1)(\mathrm{Hbpmp})-$ $\left.\left(\mathrm{H}_{2} \mathrm{O}\right)_{2}\right]_{n}(3), \quad\left[\mathrm{Co}_{2}\left(\mu_{2}-\mathrm{OH}\right)(\mathrm{HL} 1)(\mathrm{bpmp})\left(\mathrm{H}_{2} \mathrm{O}\right)_{4}\right]_{n}(4),\left\{\left[\mathrm{Co}_{2}(\mathrm{~L} 2)-\right.\right.$ $\left(\right.$ bpfp) $\left.\left.\left(\mathrm{H}_{2} \mathrm{O}\right)_{2}\right] \cdot 4 \mathrm{H}_{2} \mathrm{O}\right\}_{n}(5),\left\{\left[\mathrm{Co}_{2}(\mathrm{~L} 2)_{2}(\mathrm{bpe})_{2}\left(\mathrm{H}_{2} \mathrm{O}\right)_{2} \cdot 2 \mathrm{H}_{2} \mathrm{O}\right] \cdot\left(\mathrm{NH}_{4}\right)_{4}\right\}_{n}$ (6) were synthesized. These six complexes were characterized by elemental analysis, infrared (IR) spectroscopy, thermogravimetric analysis (TGA), single-crystal X-ray diffraction, powder X-ray diffraction (PXRD) and fluorescence spectroscopy. Desorption of lattice water molecules in complexes $\mathbf{1}$ and $\mathbf{2}$ was investigated and the values of water vapor uptake are $15.17 \mathrm{~mL} \mathrm{~g}^{-1}$ and 27.24 $\mathrm{mL} \mathrm{g}^{-1}$, respectively (Scheme 1).

\section{Experimental section}

\section{Materials and methods}

All reagents and solvents were obtained commercially without further purification. $\mathrm{Mn}(\mathrm{OAc})_{2} \cdot 4 \mathrm{H}_{2} \mathrm{O}, \mathrm{Ni}\left(\mathrm{NO}_{3}\right)_{2} \cdot 6 \mathrm{H}_{2} \mathrm{O}$ and $\mathrm{Co}\left(\mathrm{NO}_{3}\right)_{2} \cdot 6 \mathrm{H}_{2} \mathrm{O}$ are from Beijing Tong Guang Fine Chemicals Company, and the purity are $99 \% . \mathrm{H}_{4} \mathrm{~L} 1, \mathrm{H}_{4} \mathrm{~L} 2$, bpfp, bep, bpmp ligands are from Jinan Camolai Trading Company, and the purity are $98 \%$. Elemental analysis for $\mathrm{C}, \mathrm{H}$ and $\mathrm{N}$ were performed on a Perkin-Elmer $2400 \mathrm{CHN}$ elemental analyzer. The IR spectra were recorded (as $\mathrm{KBr}$ pressed pellets) on a Nicolet 170SX spectrometer in the range of $4000-400 \mathrm{~cm}^{-1}$. TGA were carried out on a Exstar SII TG/DTA 7200 thermal analyzer from room temperature to $800{ }^{\circ} \mathrm{C}$ with a heating rate of $10^{\circ} \mathrm{C} \mathrm{min}{ }^{-1}$ under the protection of nitrogen. Powder PXRD patterns were obtained using a Siemens D5005 diffractometer $(\mathrm{Cu} \mathrm{K} \alpha$ radiation, $\lambda=1.5410 \AA$ ) with the $2 \theta$ from 5 to $55^{\circ}$ under the $0.03^{\circ}$ scan step. Fluorescence spectra were recorded on a Hitachi F-4600 fluorescence/phosphorescence spectrophotometer with a xenon lamp light source. The magnetic measurements were performed on the Quantum Design SQUID PPMS60000 instruments in a magnetic field of 1000 Oe in the temperature range of 1.8-300 K. The $2 \mathrm{D}$ and 3D models for complexes 1-6 were derived with Topos4.0 software.

\section{Synthesis of $\left\{\left[\mathrm{Mn}_{2}(\mathrm{L1})(\mathrm{bpfp})\left(\mathrm{H}_{2} \mathrm{O}\right)_{2}\right] \cdot \mathbf{6} \mathrm{H}_{2} \mathrm{O} \cdot\left(\mathrm{CH}_{3} \mathrm{OH}\right)\right\}_{n}(\mathbf{1})$}

A mixture of $\mathrm{Mn}(\mathrm{OAc})_{2} \cdot 4 \mathrm{H}_{2} \mathrm{O}(73.5 \mathrm{mg}, 0.3 \mathrm{mmol}), \mathrm{H}_{4} \mathrm{~L} 1$ (20.3 mg, $0.05 \mathrm{mmol})$, bpfp $(29.6 \mathrm{mg}, 0.1 \mathrm{mmol})$ and $\mathrm{H}_{2} \mathrm{O}(10$ $\mathrm{mL}$ ) was sealed in a $23 \mathrm{~mL}$ Teflon-lined autoclave and heated at $150^{\circ} \mathrm{C}$ for 3 days. After cooling to room temperature at a speed of $0.1{ }^{\circ} \mathrm{C} \mathrm{min}{ }^{-1}$, the colorless crystals of $\mathbf{1}(90.12 \mathrm{mg})$ were obtained and washed with distilled water. $61 \%$ yield based on $\mathrm{Mn}$. Elemental analysis for $\mathrm{C}_{39} \mathrm{H}_{46} \mathrm{Mn}_{2} \mathrm{~N}_{4} \mathrm{O}_{19}$, calcd (\%): C, 47.53; H, $4.67 ; \mathrm{N}, 5.68$. Found (\%): C, 47.48; H, 4.73; N, 5.62. IR data (KBr, $\mathrm{cm}^{-1}$ ): 3406 (s), $3011(\mathrm{w}), 1523(\mathrm{~s}), 1441$ (s), 1353 (s), $1262(\mathrm{~m})$, $1166(\mathrm{w}), 1084(\mathrm{~m}), 912(\mathrm{w}), 890(\mathrm{~m}), 832(\mathrm{~m}), 801(\mathrm{~m}), 767(\mathrm{~m})$, $680(\mathrm{~m}), 576(\mathrm{w}), 527(\mathrm{w})$.

\section{Synthesis of $\left\{\left[\mathrm{Mn}_{4}\left(\mu_{3}-\mathrm{O}\right)_{2}(\mathrm{L1})_{2}(\mathrm{bpe})_{2}\left(\mathrm{H}_{2} \mathrm{O}\right)_{2}\right] \cdot 2 \mathrm{H}_{2} \mathrm{O}\right\}_{n}(2)$}

A mixture of $\mathrm{Mn}(\mathrm{OAc})_{2} \cdot 4 \mathrm{H}_{2} \mathrm{O}(73.5 \mathrm{mg}, 0.3 \mathrm{mmol}), \mathrm{H}_{4} \mathrm{~L} 1$ (20.3 mg, $0.05 \mathrm{mmol})$, bpe ( $9.1 \mathrm{mg}, 0.05 \mathrm{mmol}), \mathrm{H}_{2} \mathrm{O}(10 \mathrm{~mL})$ and $1 \mathrm{~mol} \mathrm{~L}^{-1} \mathrm{HCl}$ aqueous solution $(0.05 \mathrm{~mL})$ was sealed in a $23 \mathrm{~mL}$ Teflon-lined autoclave and heated at $150{ }^{\circ} \mathrm{C}$ for 3 days. After cooling to room temperature at a speed of $0.1^{\circ} \mathrm{C} \mathrm{min}^{-1}$, the colorless crystals of $2(23.52 \mathrm{mg})$ were obtained and washed with distilled water. $21 \%$ yield based on $\mathrm{Mn}$. Elemental analysis for $\mathrm{C}_{68} \mathrm{H}_{48} \mathrm{Mn}_{4} \mathrm{~N}_{4} \mathrm{O}_{22}$, calcd (\%): C, 54.66; H, 3.21; N, 3.75. Found (\%): C, 54.61; H, 3.27; N, 3.77. IR data $\left(\mathrm{KBr}, \mathrm{cm}^{-1}\right): 3439$ (s), 3071 (w), $1552(\mathrm{~s}), 1405(\mathrm{~s}), 1352(\mathrm{~m}), 1268(\mathrm{w}), 1130(\mathrm{w}), 1079(\mathrm{w})$, $1026(w), 939(w), 851(w), 771(\mathrm{~m}), 686(\mathrm{w}), 549(\mathrm{w})$.

\section{Synthesis of $\left[\mathrm{Ni}(\mathrm{HL1})(\mathrm{Hbpmp})\left(\mathrm{H}_{2} \mathrm{O}\right)_{2}\right]_{n}(3)$}

A mixture of $\mathrm{Ni}\left(\mathrm{NO}_{3}\right)_{2} \cdot 6 \mathrm{H}_{2} \mathrm{O}(87.3 \mathrm{mg}, 0.3 \mathrm{mmol}), \mathrm{H}_{4} \mathrm{~L} 1$ (20.3 mg, $0.05 \mathrm{mmol}$ ), bpmp (13.4 mg, $0.05 \mathrm{mmol}), \mathrm{H}_{2} \mathrm{O}(10 \mathrm{~mL})$ and $1 \mathrm{~mol} \mathrm{~L}^{-1} \mathrm{NaOH}$ aqueous solution $(0.05 \mathrm{~mL})$ was sealed in a $23 \mathrm{~mL}$ Teflon-lined autoclave and heated at $150{ }^{\circ} \mathrm{C}$ for 3 days. After cooling to room temperature at a speed of $0.1{ }^{\circ} \mathrm{C} \mathrm{min}^{-1}$, the green crystals of $3(108.32 \mathrm{mg})$ were obtained and washed with distilled water. $47 \%$ yield based on Ni. Elemental analysis for $\mathrm{C}_{38} \mathrm{H}_{36} \mathrm{NiN}_{4} \mathrm{O}_{10}$, calcd (\%): C, 59.42; H, 4.69; N, 7.30. Found (\%): C, 59.39; H, 4.64; N, 7.27. IR data $\left(\mathrm{KBr}, \mathrm{cm}^{-1}\right): 3445$ (s), 3012 (w), $1556(\mathrm{~s}), 1441(\mathrm{~s}), 1361(\mathrm{~s}), 1242(\mathrm{~m}), 1128(\mathrm{w}), 1070(\mathrm{~m}), 914$ (w), $899(\mathrm{~m}), 839(\mathrm{~m}), 768(\mathrm{~m}), 672(\mathrm{~m}), 587(\mathrm{w}), 524(\mathrm{w})$.

\section{Synthesis of $\left[\mathrm{Co}_{2}\left(\mu_{2}-\mathrm{OH}\right)(\mathrm{HL1})(\mathrm{bpmp})\left(\mathrm{H}_{2} \mathrm{O}\right)_{4}\right]_{n}(4)$}

A mixture of $\mathrm{Co}\left(\mathrm{NO}_{3}\right)_{2} \cdot 6 \mathrm{H}_{2} \mathrm{O}(87.1 \mathrm{mg}, 0.3 \mathrm{mmol}), \mathrm{H}_{4} \mathrm{~L} 1$ (20.3 mg, $0.05 \mathrm{mmol})$, bpmp $(26.8 \mathrm{mg}, 0.1 \mathrm{mmol})$ and $\mathrm{H}_{2} \mathrm{O}(10$ $\mathrm{mL}$ ) was sealed in a $23 \mathrm{~mL}$ Teflon-lined autoclave and heated at $150{ }^{\circ} \mathrm{C}$ for 3 days. After cooling to room temperature at a speed of $0.1{ }^{\circ} \mathrm{C} \mathrm{min}{ }^{-1}$, the red crystals of $4(48.66 \mathrm{mg})$ were obtained and washed with distilled water. $37 \%$ yield based on Co. Elemental analysis for $\mathrm{C}_{38} \mathrm{H}_{40} \mathrm{Co}_{2} \mathrm{~N}_{4} \mathrm{O}_{13}$, calcd (\%): C, $51.90 ; \mathrm{H}$, 4.55; N, 6.37. Found (\%): C, 51.88; H, 4.57; N, 6.33. IR data (KBr, $\mathrm{cm}^{-1}$ ): $3558(\mathrm{~s}), 3231(\mathrm{~s}), 1522(\mathrm{~s}), 1394(\mathrm{~s}), 1261(\mathrm{~m}), 1155(\mathrm{w})$, $1125(\mathrm{w}), 1051(\mathrm{w}), 966(\mathrm{w}), 851(\mathrm{~m}), 778(\mathrm{~m}), 670(\mathrm{w}), 570(\mathrm{w})$, $514(\mathrm{w})$.

\section{Synthesis of $\left\{\left[\mathrm{Co}_{2}(\mathrm{~L} 2)(\mathrm{bpfp})\left(\mathrm{H}_{2} \mathrm{O}\right)_{2}\right] \cdot \mathbf{4} \mathrm{H}_{2} \mathrm{O}\right\}_{n}(5)$}

A mixture of $\mathrm{Co}\left(\mathrm{NO}_{3}\right)_{2} \cdot 6 \mathrm{H}_{2} \mathrm{O}(17.5 \mathrm{mg}, 0.06 \mathrm{mmol}), \mathrm{H}_{4} \mathrm{~L} 2$ ( $8.1 \mathrm{mg}, 0.02 \mathrm{mmol}$ ), bpfp (17.7 mg, $0.06 \mathrm{mmol}), \mathrm{H}_{2} \mathrm{O}(10 \mathrm{~mL})$ and $1 \mathrm{~mol} \mathrm{~L}^{-1} \mathrm{NaOH}$ aqueous solution $(0.1 \mathrm{~mL})$ was sealed in a $23 \mathrm{~mL}$ Teflon-lined autoclave and heated at $160{ }^{\circ} \mathrm{C}$ for 3 days. After cooling to room temperature at a speed of $0.1{ }^{\circ} \mathrm{C} \mathrm{min}{ }^{-1}$, the red crystals of $5(3.06 \mathrm{mg})$ were obtained and washed with distilled water. $11 \%$ yield based on Co. Elemental analysis for $\mathrm{C}_{38} \mathrm{H}_{38} \mathrm{Co}_{2} \mathrm{~N}_{4} \mathrm{O}_{16}$, calcd (\%): C, 49.32; H, 4.11; N, 6.05. Found (\%): C, 49.35; H, 4.14; N, 6.00. IR data $\left(\mathrm{KBr}, \mathrm{cm}^{-1}\right): 3440(\mathrm{~s}), 1641$ (m), 1549 (s), $1504(\mathrm{~s}), 1442(\mathrm{~m}), 1371(\mathrm{~s}), 1260(\mathrm{~m}), 1192(\mathrm{~s})$, $1138(\mathrm{~s}), 1060(\mathrm{~s}), 1026(\mathrm{w}), 951(\mathrm{w}), 880(\mathrm{w}), 798(\mathrm{~m}), 727(\mathrm{w}), 630$ $(\mathrm{w}), 502(\mathrm{w})$.

\section{Synthesis of $\left\{\left[\mathrm{Co}_{2}(\mathrm{~L} 2)_{2}(\mathrm{bpe})_{2}\left(\mathrm{H}_{2} \mathrm{O}\right)_{2} \cdot 2 \mathrm{H}_{2} \mathrm{O}\right] \cdot\left(\mathrm{NH}_{4}\right)_{4}\right\}_{n}(6)$}

A mixture of $\mathrm{Co}\left(\mathrm{NO}_{3}\right)_{2} \cdot 6 \mathrm{H}_{2} \mathrm{O}(58.2 \mathrm{mg}, 0.2 \mathrm{mmol}), \mathrm{H}_{4} \mathrm{~L} 2$ (40.6 mg, $0.1 \mathrm{mmol}$ ), bpe $(36.4 \mathrm{mg}, 0.2 \mathrm{mmol}), \mathrm{H}_{2} \mathrm{O}(10 \mathrm{~mL})$ and $1 \mathrm{~mol} \mathrm{~L}^{-1} \mathrm{HCl}$ aqueous solution $(0.05 \mathrm{~mL})$ was sealed in a $23 \mathrm{~mL}$ Teflon-lined autoclave and heated at $150{ }^{\circ} \mathrm{C}$ for 3 days. After cooling to room temperature at a speed of $0.1^{\circ} \mathrm{C} \mathrm{min}^{-1}$, the red crystals of $6(10.02 \mathrm{mg})$ were obtained and washed with distilled water. $7 \%$ yield based on Co. Elemental analysis for $\mathrm{C}_{68} \mathrm{H}_{64} \mathrm{Co}_{2} \mathrm{~N}_{8} \mathrm{O}_{20}$, calcd (\%): C, 57.02; H, 4.47; N, 7.82. Found 
(\%): C, 57.05; H, 4.44; N, 7.84. IR data $\left(\mathrm{KBr}, \mathrm{cm}^{-1}\right): 3417(\mathrm{w})$, 3030 (m), 2772 (m), 2432 (m), 1655 (s), 1561 (s), 1481 (m), 1401 (s), 1355 (s), 1261 (m), 1108 (m), 1026 (m), 921 (w), 849 (m), 783 (m), $660(\mathrm{w}), 575(\mathrm{w}), 531(\mathrm{w}), 502(\mathrm{w})$.

\section{Single-crystal X-ray crystallography}

Single-crystal X-ray diffraction data for complexes 1-6 were collected on a Bruker APEX diffractometer with Mo K $\alpha$ radiation (graphite monochromator, $\lambda=0.71073 \AA$ ) at 298(2) K. The structures of complexes 1-6 were solved by direct methods and refined by full-matrix least-squares methods on $F^{2}$ using SHELXTL crystallographic software package. ${ }^{18}$ All the nonhydrogen atoms were refined anisotropically. The hydrogen atoms of the organic ligands were generated theoretically on to the specific atoms and refined isotropically through fixed thermal factors. The crystallographic data and structure refinement parameters of complexes 1-6 are listed in Table 1. The selected bond distances $(\AA)$ and angles $\left({ }^{\circ}\right)$ for complexes 1-6 are summarized in Table $\mathrm{S} 1$ (ESI $\dagger$ ). The hydrogen bond parameters of complexes 2, 3, 4, 6 are presented in Table S2 (ESI $\dagger$ ). The CCDC reference numbers are 1056874-1056879 for complexes 1-6.

\section{Results and discussion}

\section{Description of crystal structures}

Crystal structure of $\left\{\left[\mathrm{Mn}_{2}(\mathrm{L1})(\mathrm{bpfp})\left(\mathrm{H}_{2} \mathrm{O}\right)_{2}\right] \cdot 6 \mathrm{H}_{2} \mathrm{O} \cdot\left(\mathrm{CH}_{3}-\right.\right.$ $\mathbf{O H})\}_{n}$ (1). Structural analysis indicates that complex $\mathbf{1}$ is a $3 \mathrm{D}$ framework containing 2D Mn-L1 coordination layers. Complex $\mathbf{1}$ crystallizes in the triclinic $P \overline{1}$ space group, and the asymmetric unit is composed of one $\mathrm{Mn}^{\mathrm{II}}$ ion, one half of $\mathrm{L} 1$ ligand, one half of bpfp ligand, one coordinated water molecule, three free water molecules and one half of free methanol molecule. Mn1 is coordinated by four carboxylic oxygen atoms from three separate L1 ligands, one pyridine nitrogen atom from bpfp ligand and one coordinated water molecule, adopting $\left\{\mathrm{MnO}_{5} \mathrm{~N}\right\}$ coordination geometry (Fig. 2a). The distances of $\mathrm{Mn}-\mathrm{O}$ are in the range of 2.093(3)-2.265(3) $\AA$ and the distance of Mn1-N1 is 2.208(4) Å. The completely deprotonated L1 ligand exhibits $\mu_{1}$ $\eta^{1}: \eta^{1}$ and $\mu_{2}-\eta^{1}: \eta^{1}$ coordination modes (Fig. 1a). The lateral phenyl rings are parallel. The dihedral angles between lateral phenyl rings and the central phenyl ring are both $44.03^{\circ}$. The $\mu_{6}$ bridging $\mathrm{L} 1$ ligands are linked by $\mathrm{Mn}^{\mathrm{II}}$ ions to generate a $2 \mathrm{D}$ coordination layer structure (Fig. 2 b), and the $\mu_{2}$-bridging $\mathrm{N}$ donor bpfp ligands with the parallel pyridine rings link the neighbouring 2D layer structures to produce a 3D framework (Fig. S2 $\dagger$ ).

From a topological viewpoint, Mn1 is coordinated by three L1 ligands and one bpfp ligand, which is considered as 4-connected node. The L1 ligand linking six Mn1 is considered as 6connected node, and the bpfp ligand acts as a linker connecting two MnII metal ions. Therefore, the 3D structure can be generalized as a $(4,6)$-connected net with the Schläfli symbol of $\left\{4^{3} \cdot 6^{3}\right\}_{2}\left\{4^{6} \cdot 6^{6} \cdot 8^{3}\right\}$ (Fig. 2c). The topology type has been reported by our group. ${ }^{19}$

Crystal structure of $\left\{\left[\mathrm{Mn}_{4}\left(\mu_{3}-\mathrm{O}\right)_{2}(\mathrm{L1})_{2}(\mathrm{bpe})_{2}\left(\mathrm{H}_{2} \mathrm{O}\right)_{2}\right] \cdot 2 \mathbf{H}_{2} \mathrm{O}\right\}_{n}$ (2). Compared with complex $\mathbf{1}$, bpfp ligand was replaced by bpe ligand, and 2D layer with $(4,6)$-connected net was obtained. The X-ray crystal data reveal that complex 2 also crystallizes in the triclinic $P \overline{1}$ space group. The asymmetric unit is made up of two crystallographically independent $\mathrm{Mn}^{\mathrm{II}}$ ions, one L1 ligand, one bpe ligand, one coordinated water molecule, one $\mu_{3}-\mathrm{O}$ and one free water molecule (Fig. 3a). Mn1 is located in a distorted $\left\{\mathrm{MnO}_{6}\right\}$ square-pyramidal coordination configuration, which is surrounded by five oxygen atoms from three carboxylic oxygen atoms (O1, O3, O7) of three separate L1 ligands, one oxygen

Table 1 Crystal data and structure refinement for complexes 1-6

\begin{tabular}{|c|c|c|c|c|c|c|}
\hline Complex & 1 & 2 & 3 & 4 & 5 & 6 \\
\hline Formula & $\mathrm{C}_{39} \mathrm{H}_{46} \mathrm{Mn}_{2} \mathrm{~N}_{4} \mathrm{O}_{19}$ & $\mathrm{C}_{68} \mathrm{H}_{48} \mathrm{Mn}_{4} \mathrm{~N}_{4} \mathrm{O}_{22}$ & $\mathrm{C}_{38} \mathrm{H}_{36} \mathrm{NiN}_{4} \mathrm{O}_{10}$ & $\mathrm{C}_{38} \mathrm{H}_{40} \mathrm{Co}_{2} \mathrm{~N}_{4} \mathrm{O}_{13}$ & $\mathrm{C}_{38} \mathrm{H}_{38} \mathrm{Co}_{2} \mathrm{~N}_{4} \mathrm{O}_{16}$ & $\mathrm{C}_{68} \mathrm{H}_{64} \mathrm{Co}_{2} \mathrm{~N}_{8} \mathrm{O}_{20}$ \\
\hline Formula wt & 984.68 & 1492.86 & 767.42 & 878.60 & 924.58 & 1431.13 \\
\hline Cryst. syst. & Triclinic & Triclinic & Monoclinic & Triclinic & Triclinic & Triclinic \\
\hline$a(\AA)$ & $10.2909(9)$ & $11.4630(9)$ & $13.5450(12)$ & $12.3610(11)$ & $8.5810(7)$ & $10.7230(9)$ \\
\hline$b(\AA)$ & $10.6550(10)$ & $11.8350(10)$ & $20.0472(18)$ & $12.7309(12)$ & $10.2780(8)$ & $11.8829(11)$ \\
\hline$c(\AA)$ & $11.4221(11)$ & $11.8930(11)$ & $12.8501(11)$ & $12.7571(14)$ & $12.2140(11)$ & $13.6481(12)$ \\
\hline$\gamma\left({ }^{\circ}\right)$ & $61.9060(10)$ & $87.414(2)$ & 90 & 70.9820 & $68.8610(10)$ & $78.075(2)$ \\
\hline$V\left(\AA^{3}\right)$ & $1066.09(17)$ & $1550.4(2)$ & $3488.3(5)$ & $1876.4(3)$ & $951.03(14)$ & $1600.0(2)$ \\
\hline$Z$ & 1 & 1 & 4 & 2 & 1 & 1 \\
\hline$D_{\text {calc }}\left(\mathrm{g} \mathrm{cm}^{-3}\right)$ & 1.534 & 1.599 & 1.461 & 1.555 & 1.614 & 1.485 \\
\hline$\mu\left(\mathrm{mm}^{-1}\right)$ & 0.677 & 0.883 & 0.623 & 0.957 & 0.955 & 0.603 \\
\hline$F(000)$ & 510 & 760 & 1600 & 908 & 476 & 742 \\
\hline$\Delta \rho_{\max }\left(\mathrm{e} \AA^{-3}\right)$ & 0.603 & 1.108 & 0.544 & 1.520 & 1.584 & 0.862 \\
\hline$\Delta \rho_{\min }\left(\mathrm{e} \AA^{-3}\right)$ & -0.519 & -0.971 & -0.397 & -0.942 & -0.968 & -0.499 \\
\hline
\end{tabular}


(a)

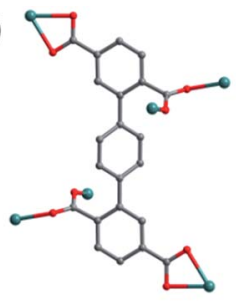

(d)

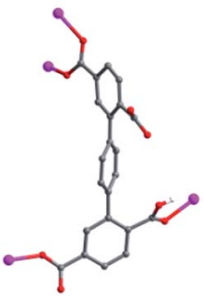

(b)

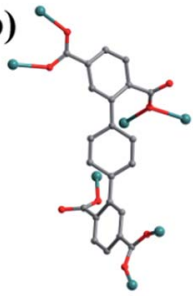

(e)

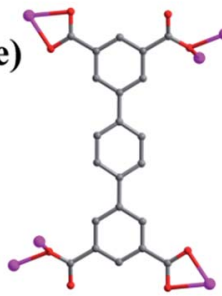

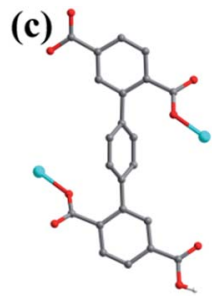

(f)

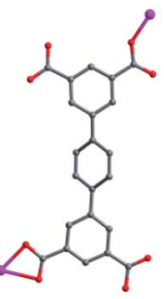

Fig. 1 Coordination modes of $\mathrm{H}_{4} \mathrm{~L} 1$ and $\mathrm{H}_{4} \mathrm{~L} 2$ ligands in complexes $1-$ 6. (a) Complex 1; (b) complex 2; (c) complex 3; (d) complex 4; (e) complex 5; (f) complex 6. Color legend: teal, $\mathrm{Mn}$; turquoise, $\mathrm{Ni}$; pink, Co; gray, C; red, O; white, $\mathrm{H}$.

atom $(\mathrm{O} 10)$ of one coordinated water molecule and one oxygen atom (O9) of $\mu_{3}-\mathrm{O}$. The distances of Mn1-O are in the range of 2.095(9)-2.501(9) $\AA$. Mn2 is located in a distorted $\left\{\mathrm{MnO}_{5} \mathrm{~N}\right\}$ octahedral coordination geometry, which is surrounded with five oxygen atoms and one nitrogen atom from three carboxylic oxygen atoms $(\mathrm{O} 4 \mathrm{~A}, \mathrm{O}, \mathrm{O}$ - $\mathrm{A})$ of three separate L1 ligands, two oxygen atoms $(\mathrm{O} 9, \mathrm{O} 9 \mathrm{~A})$ of two separate $\mu_{3}-\mathrm{O}$ and one nitrogen atom (N1) of one bpe ligand. The distances of $\mathrm{Mn} 2-\mathrm{O}$ are in the range of 2.149(10)-2.323(9) $\AA$ and the distance of Mn2-N1 is $2.342(12) \AA$. The completely deprotonated L1 ligand displays $\mu_{1}$ $\eta^{1}: \eta^{0}, \mu_{2}-\eta^{2}: \eta^{0}$ and $\mu_{2}-\eta^{1}: \eta^{1}$ coordination patterns (Fig. 1b). The bpe acts as terminal ligand linking with $\mathrm{Mn} 2$. The dihedral angle between the lateral phenyl rings is $82.81^{\circ}$, while the dihedral angles between lateral phenyl rings and the central phenyl ring are $37.52^{\circ}$ and $45.49^{\circ}$, respectively. Each $\mu_{6}$-bridging L1 ligand is linked by dinuclear $\mathrm{Mn}^{\mathrm{II}}$ units to form a $(3,6)$ connected 2D layer with the Schläfli symbol of $\left\{4^{3}\right\}_{2}\left\{4^{6} \cdot 6^{6} \cdot 8^{3}\right\}$ (Fig. 3b and S3 $\dagger$ ). The topology type has been reported by Zhao' group. ${ }^{20}$

The 2D layer is further extended to generate a 3D supramolecular framework by three types of hydrogen-bonding interactions (Fig. 3c). The distance of $\mathrm{O} 10-\mathrm{H} 10 \mathrm{D} \cdots \mathrm{O} 2$ formed between the coordinated water molecule and the carboxylic oxygen atom is $2.767 \AA$. $\mathrm{O} 10-\mathrm{H} 10 \mathrm{E} \cdots \mathrm{N} 2$ is formed between the coordinated water molecule and the bpe ligand with the distance of $2.797 \AA$. O11-H11C $\cdots \mathrm{O} 2$ and $011-\mathrm{H} 11 \mathrm{D} \cdots \mathrm{O} 6$ are formed between the lattice water molecules and the carboxylic oxygen atoms with the distances of $3.029 \AA$ and $2.906 \AA$, respectively.

Crystal structure of $\left[\mathrm{Ni}(\mathrm{HL} 1)(\mathrm{Hbpmp})\left(\mathrm{H}_{2} \mathrm{O}\right)_{2}\right]_{n}$ (3). Singlecrystal X-ray structural analysis shows that complex 3 belongs to the monoclinic $P 2_{1} / c$ space group. The asymmetric unit has one $\mathrm{Ni}^{\mathrm{II}}$ ion, one HL1 ligand, one protonated Hbpmp ligand and two coordinated water molecules. The $\mathrm{Ni}^{\mathrm{II}}$ metal ion is surrounded by two oxygen atoms (O1, O5A) from two separate HL1 ligands, two nitrogen atoms (N3, N4) from Hbpmp ligands and two oxygen atoms (O9, O10) from two

(a)

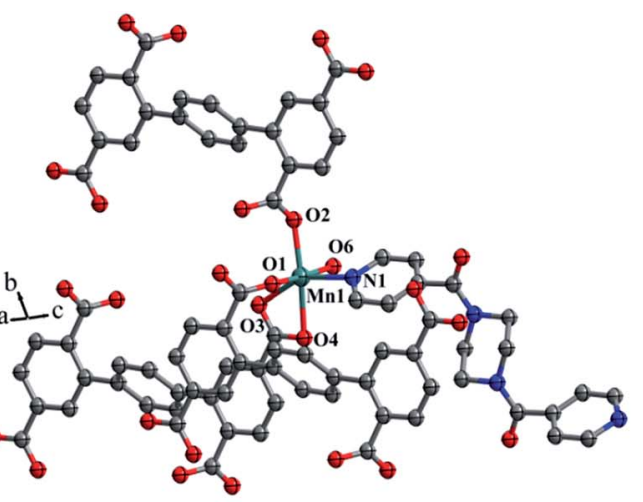

(b)

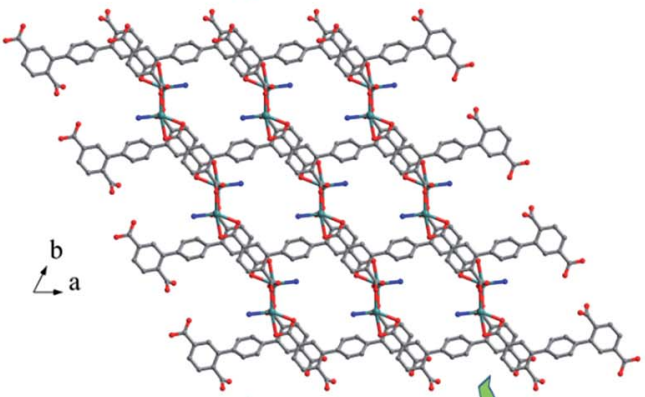

(c)

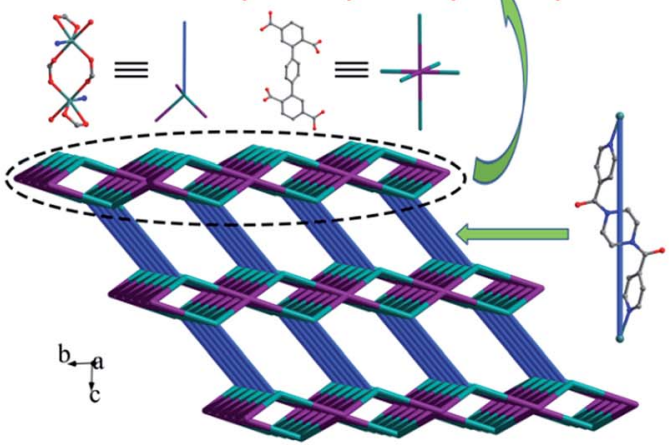

Fig. 2 (a) Coordination environment of the $\mathrm{Mn}^{\text {"I }}$ ion in complex 1 ; (b) $2 D$ layer structure in 1 ; (c) schematic of the $(4,6)$-connected 3D framework with $\left\{4^{3} \cdot 6^{3}\right\}_{2}\left\{4^{6} \cdot 6^{6} \cdot 8^{3}\right\}$ topology. Color legend: teal, $\mathrm{Mn}$; gray, $\mathrm{C}$; blue, $\mathrm{N}$; red, $\mathrm{O}$. All hydrogen atoms, the lattice $\mathrm{H}_{2} \mathrm{O}$ and $\mathrm{CH}_{3} \mathrm{OH}$ are omitted for clarity.

coordinated water molecules, displaying a distorted $\left\{\mathrm{NiO}_{4} \mathrm{~N}_{2}\right\}$ octahedral coordination configuration (Fig. 4a). The coordinated water molecules are in trans configuration. The distances of $\mathrm{Ni}-\mathrm{O}$ are in the range of 2.023(2)-2.146(2) $\AA$, and $\mathrm{Ni}-\mathrm{N}$ are 2.111(2) $\AA$, 2.118(2) $\mathrm{A}$. The partially deprotonated HL1 ligands adopt $\mu_{1}-\eta^{1}: \eta^{0}$ patterns linking with $\mathrm{Ni}^{\mathrm{II}}$ ion (Fig. 1c). The dihedral angle between the lateral phenyl rings is $4.78^{\circ}$. The dihedral angles between lateral phenyl rings and the central phenyl ring are $59.34^{\circ}$ and $63.83^{\circ}$, respectively. Each $\mu_{2}$-bridging $\mathrm{HL} 1$ ligand is connected by $\mathrm{Ni}^{\mathrm{II}}$ metal ions to form a "Z"-type 1D chain, and two nitrogen atoms from bis-pyridine Hbpmp ligands link $\mathrm{Ni}^{\mathrm{II}}$ metal ions to form a $1 \mathrm{D}$ chair-like chain (Fig. 4b), displaying a 4-connected 2D layer with the Schläfli symbol of $\left\{4^{4} \cdot 6^{2}\right\}$ (Fig. S4†).

The 3D supramolecular framework is generated by hydrogen-bonding interactions between the coordinated water molecules (O10) and carboxylic oxygen atoms (O7). The distance of the $\mathrm{O} 10-\mathrm{H} 10 \mathrm{D} \cdots \mathrm{O} 7$ hydrogen bond is $2.741 \AA$ (Fig. 4c). 

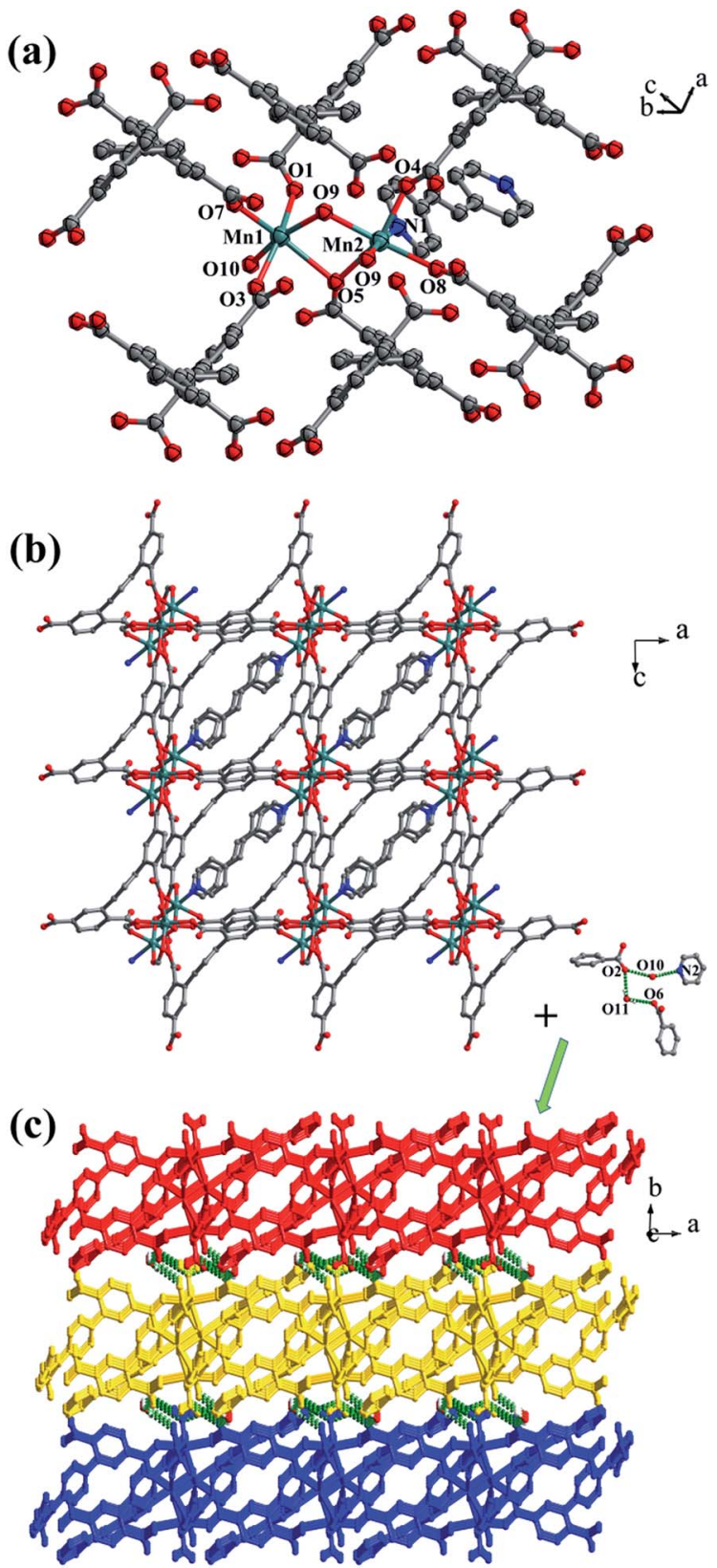

Fig. 3 (a) Coordination environment of the $\mathrm{Mn}^{\text {II }}$ ion in complex 2; (b) 2D layer structure in 2; (c) 3D supramolecular framework formed by hydrogen-bonding interactions in 2. Color legend: teal, Mn; gray, C; blue, $\mathrm{N}$; red, $\mathrm{O}$. All hydrogen atoms from ligands are omitted for clarity.

Crystal structure of $\left[\mathrm{Co}_{2}\left(\mu_{2}-\mathrm{OH}\right)(\mathrm{HL1})(\mathrm{bpmp})\left(\mathrm{H}_{2} \mathrm{O}\right)_{4}\right]_{n}$ (4). The space group of complex $\mathbf{4}$ is triclinic $P \overline{1}$, and complex $\mathbf{4}$ is a 3D supramolecular framework based on 4-connected 2D layer. The asymmetric unit is composed of two crystallographically independent $\mathrm{Co}^{\mathrm{II}}$ ions, one HL1 ligand, one bpmp ligand, four coordinated water molecules and one $\mu_{2}-\mathrm{OH}$ (Fig. 5a). Co1 and Co2 are all located in distorted octahedral configuration, which are bonded by one hydroxyl oxygen atom (O9). Co1 and $\mathrm{Co} 2$ are coordinated with two oxygen atoms (O3 and $\mathrm{O} 7$ for $\mathrm{Co1}, \mathrm{O} 4$ and $\mathrm{O} 6 \mathrm{~A}$ for $\mathrm{Co} 2$ ) from carboxyl groups of two separated HL1 ligands, one nitrogen atom (N1 for Co1, N3 (a)

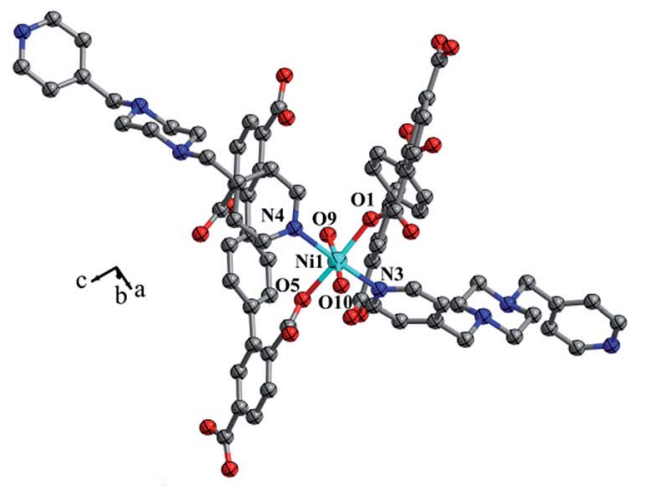

(b)
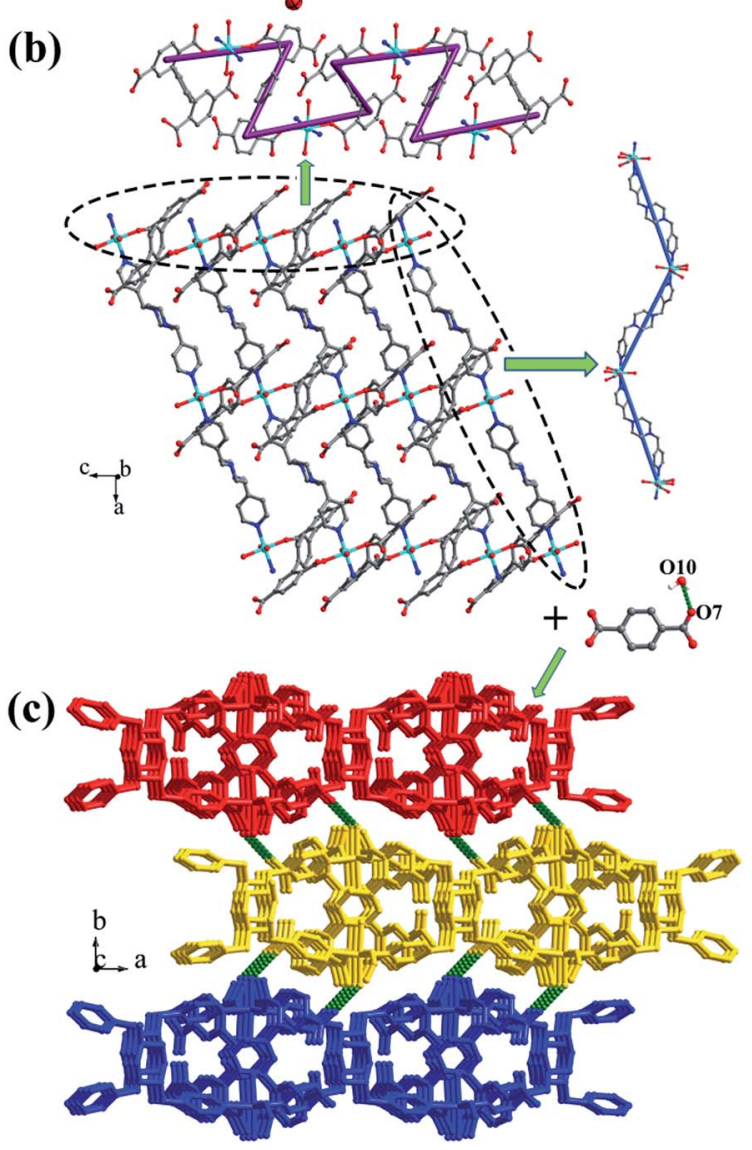

Fig. 4 (a) Coordination environment of the $\mathrm{Ni}^{\text {ll }}$ ion in complex 3; (b) 2D layer structure with two types of $1 D$ chain in 3; (c) 3D supramolecular framework formed by hydrogen-bonding interactions in 3 . Color legend: turquoise, $\mathrm{Ni}$; gray, $\mathrm{C}$; blue, $\mathrm{N}$; red, O. All hydrogen atoms from ligands are omitted for clarity.

for Co2) of two separated bpmp ligands, two oxygen atoms (O10 and $\mathrm{O} 11$ for $\mathrm{Co1}, \mathrm{O} 12$ and $\mathrm{O} 13$ for $\mathrm{Co} 2$ ) from the coordinated water molecules and one hydroxyl oxygen atom (O9). The distances are in the range of 2.068(8)-2.298(8) $\AA$ for Co1, 2.056(8)-2.201(7) $\AA$ for $\mathrm{Co} 2$, and the distances of Co1-N1 and Co2-N3 are 2.221(10) $\AA, 2.153(9) \AA$, respectively. The partially deprotonated HL1 ligand possesses two kinds of coordination patterns: monodentate $\mu_{1}-\eta^{1}: \eta^{0}$ and bidentate $\mu_{2}-$ $\eta^{1}: \eta^{1}$ (Fig. 1d). The dihedral angle between lateral phenyl rings is $75.93^{\circ}$, and the dihedral angles are $50.58^{\circ}$ and $53.56^{\circ}$ between the lateral phenyl rings and the central phenyl ring, 
(a)

(c)
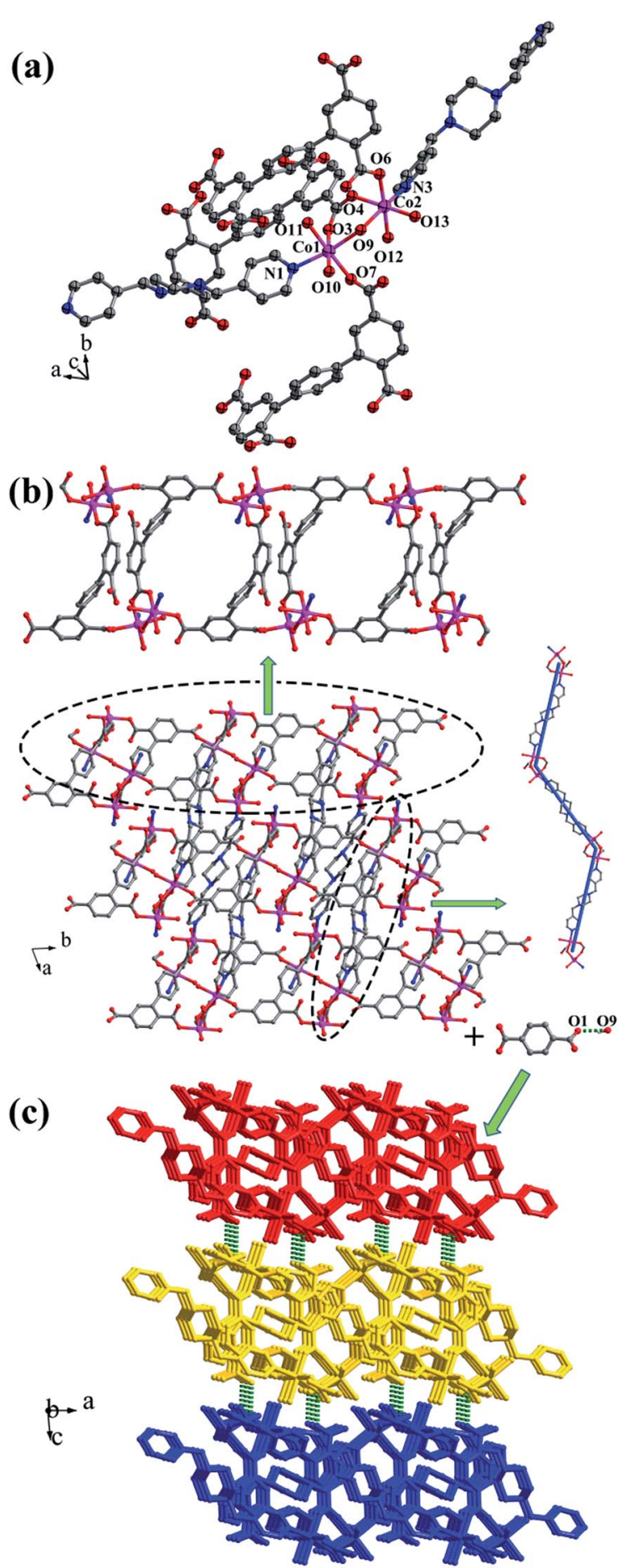

Fig. 5 (a) Coordination environment of the Co" ion in complex 4; (b) 2D layer structure with two types of $1 \mathrm{D}$ chain in 4; (c) 3D supramolecular framework formed by hydrogen-bonding interactions in 4 . Color legend: pink, Co; gray, C; blue, N; red, O. All hydrogen atoms from ligands are omitted for clarity.

respectively. Each $\mu_{4}$-bridging HL1 ligand is linked with $\mathrm{Co}^{\mathrm{II}}$ metal ions to form a $1 \mathrm{D}$ chain, and the $\mu_{2}$-bridging $\mathrm{N}$-donor bpmp ligands connect the neighbouring $1 \mathrm{D}$ chains to give a 4-connected 2D layer (Fig. 5b) with the Schläfli symbol of $\{4 \cdot 9 \cdot 10\}\left\{4 \cdot 9^{2}\right\}\left\{4^{2} \cdot 9 \times 10^{3}\right\}$ (Fig. S5†).
The 3D supramolecular framework is formed by $\mathrm{O}-\mathrm{H} \cdots \mathrm{O}$ hydrogen-bonding interactions between the coordinated water molecules (O9) and carboxylic oxygen atoms (O1). The distance of the O9-H9A $\cdots \mathrm{O} 1$ hydrogen bond is $2.751 \AA$ (Fig. 5c).

Crystal structure of $\left\{\left[\mathrm{Co}_{2}(\mathrm{~L} 2)(\mathrm{bpfp})\left(\mathrm{H}_{2} \mathrm{O}\right)_{2}\right] \cdot \mathbf{4} \mathrm{H}_{2} \mathrm{O}\right\}_{n}(5)$. X-ray crystal data reveal that complex $\mathbf{5}$ crystallizes triclinic $P \overline{1}$ space group, and it shows a 3D framework based on the Co-L2 coordination layers. The asymmetric unit is made up of one $\mathrm{Co}^{\mathrm{II}}$ ion, a half L2 ligand, a half bpfp ligand, one coordinated water molecule and two free water molecules. Each $\mathrm{Co}^{\mathrm{II}}$ ion is in a distorted $\left\{\mathrm{CoO}_{5} \mathrm{~N}\right\}$ coordination environment and is surrounded by four oxygen atoms $(\mathrm{O} 1, \mathrm{O} 1 \mathrm{~B}, \mathrm{O} 3 \mathrm{~A}, \mathrm{O} 4 \mathrm{~A})$ of three separate L2 ligands, one oxygen atom (O6) of coordinated water molecule and one pyridine nitrogen atom (N1) of bpfp ligand (Fig. 6a). The distances of $\mathrm{Co}-\mathrm{O}$ are in the range of 2.071(5)-

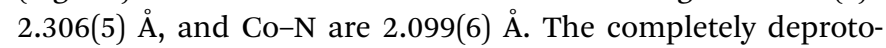
nated L2 ligand adopts two kinds of coordination patterns: $\mu_{1}$ $\eta^{1}: \eta^{1}$ and $\mu_{2}-\eta^{2}: \eta^{0}$ (Fig. 1e). The two parallel phenyl rings have a dihedral angle of $15.63^{\circ}$ with the central phenyl ring. Each $\mu_{6}$ bridging $\mathrm{L} 2$ ligand is connected with $\mathrm{Co}^{\mathrm{II}}$ metal ions to form a 2D layer (Fig. 6b), and the $\mu_{2}$-bridging $N$-donor bpfp ligands link the neighbouring 2D layers to generate a $3 \mathrm{D}$ framework (Fig. S6†).

From a topological viewpoint, Co1 ions are coordinated by three L2 ligands and one bpfp ligand, which are considered as 4-connected nodes. The L2 ligand connected with six Co1 ions is considered as 6-connected node, and the bpfp ligand acts as a linker. Therefore, the 3D structure can be simplified as a $(4,6)$ connected $\left\{4^{4} \cdot 6^{10} \cdot 8\right\}\left\{4^{4} \cdot 6^{2}\right\}$ framework (Fig. 6c).

Crystal structure of $\left\{\left[\mathrm{Co}_{2}(\mathrm{~L} 2)_{2}(\mathrm{bpe})_{2}\left(\mathrm{H}_{2} \mathrm{O}\right)_{2} \cdot 2 \mathrm{H}_{2} \mathrm{O}\right] \cdot\left(\mathrm{NH}_{4}\right)_{4}\right\}_{n}$ (6). When bpe ligand was used instead of bpfp ligand, a 3D supramolecular framework containing $(4,4)$-connected net was obtained. Single-crystal X-ray structural analysis indicates that complex 6 belongs to the triclinic $P \overline{1}$ space group. The asymmetric unit is composed of one $\mathrm{Co}^{\mathrm{II}}$ ion, one L2 ligand, one bpe ligand, one coordinated water molecule, one free water molecule and two $\mathrm{NH}_{4}{ }^{+}$. The $\mathrm{Co}^{\mathrm{II}}$ ion is surrounded by three oxygen atoms $(\mathrm{O} 1, \mathrm{O} 2, \mathrm{O} 7 \mathrm{~A})$ from two separate $\mathrm{L} 2$ ligands, two nitrogen atoms (N1, N2) from bpe ligands and one oxygen atom (O9) of coordinated water molecule, adopting a distorted $\left\{\mathrm{CoO}_{4} \mathrm{~N}_{2}\right\}$ octahedral coordination configuration (Fig. 7a). The distances of Co-O are in the range of 2.006(9)-2.304(9) $\AA$, and

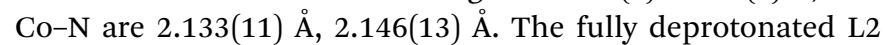
ligands possess $\mu_{1}-\eta^{1}: \eta^{0}$ and $\mu_{1}-\eta^{1}: \eta^{1}$ patterns (Fig. 1f). The dihedral angle between the lateral phenyl rings is $2.60^{\circ}$. The dihedral angles between lateral phenyl rings and the central phenyl ring are $32.58^{\circ}$. Each $\mu_{2}$-bridging L2 ligand is linked with $\mathrm{Co}^{\mathrm{II}}$ metal ions to form a wave-type $1 \mathrm{D}$ chain, and bpe ligands connected the neighbouring $\mathrm{Co}^{\mathrm{II}}$ metal ions to form a 4-connected 2D layer (Fig. 7b) with the Schläfli symbol of $\left\{4^{4} \cdot 6^{2}\right\}$ (Fig. S7†).

The $2 \mathrm{D}$ layer is further extended to form a $3 \mathrm{D}$ supramolecular framework by $\mathrm{O}-\mathrm{H} \cdots \mathrm{O}$ hydrogen-bonding interactions between the coordinated water molecules (O9) and carboxylic oxygen atoms (O8). The distance of the O9-H9D $\cdots$ O8 hydrogen bond is $2.771 \AA$ (Fig. 7c). 
(a)

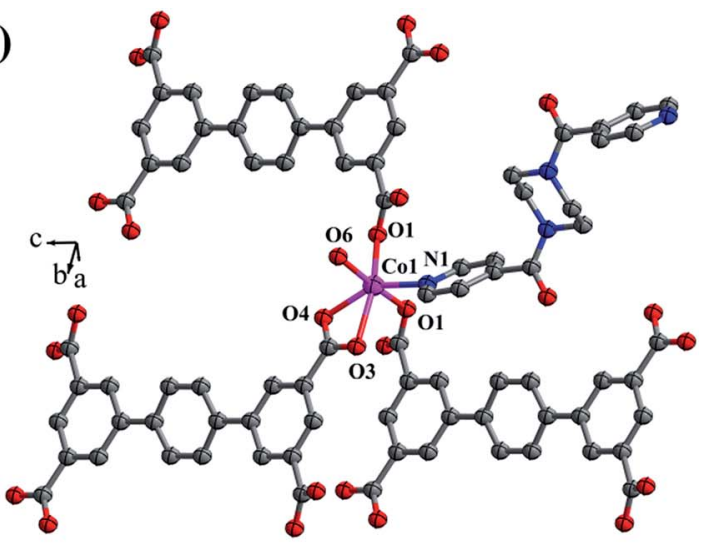

(b)

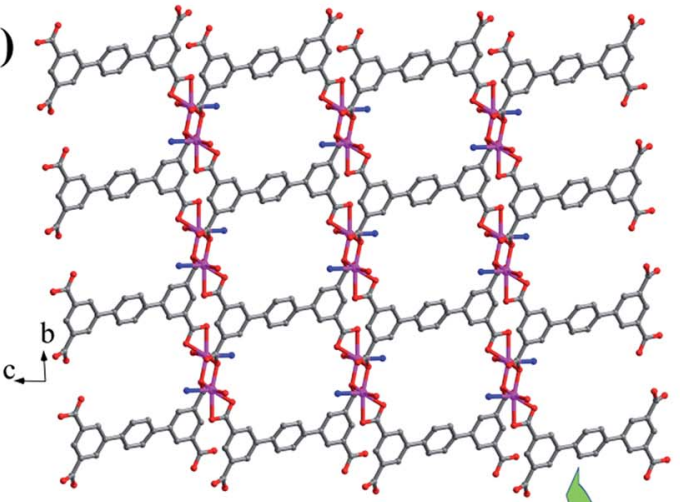

(c)
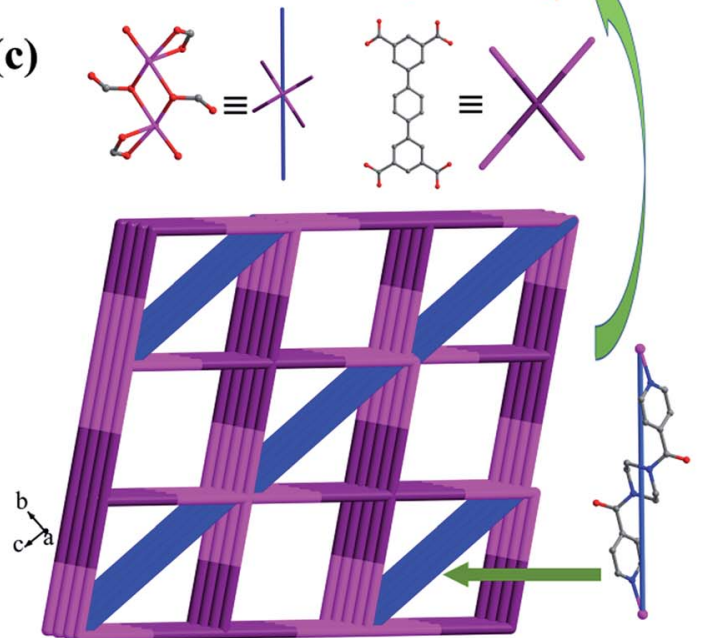

Fig. 6 (a) Coordination environment of the Co" ion in complex 5; (b) 2D layer structure in 5; (c) Schematic of the $(4,6)$-connected 3D framework with $\left\{4^{4} \cdot 6^{10} \cdot 8\right\}\left\{4^{4} \cdot 6^{2}\right\}$ topology. Color legend: pink, Co; gray, $\mathrm{C}$; blue, $\mathrm{N}$; red, $\mathrm{O}$. All hydrogen atoms and the lattice $\mathrm{H}_{2} \mathrm{O}$ are omitted for clarity.

Influence of the different bis-pyridyl ligands and metal ions on the architectures of complexes 1-6

In our work, $\left[1,1^{\prime}: 4^{\prime}, 1^{\prime \prime}\right.$-terphenyl]-2,2 $2^{\prime \prime}, 5,5^{\prime \prime}$-tetracarboxylic acid $\left(\mathrm{H}_{4} \mathrm{~L} 1\right), \quad\left[1,1^{\prime}: 4^{\prime}, 1^{\prime \prime}\right.$-terphenyl $]-3,3^{\prime \prime}, 5,5^{\prime \prime}$-tetracarboxylic acid $\left(\mathrm{H}_{4} \mathrm{~L} 2\right)$ as the main ligands react with the transition metal ions $\left(\mathrm{Mn}^{\mathrm{II}}, \mathrm{Ni}^{\mathrm{II}}\right.$ and $\left.\mathrm{Co}^{\mathrm{II}}\right)$ and different auxiliary bis-pyridyl ligands (bpfp, bpe and bpmp) to construct six 2D and 3D coordination polymers. In the structures of complexes 1 and 2 , the completely

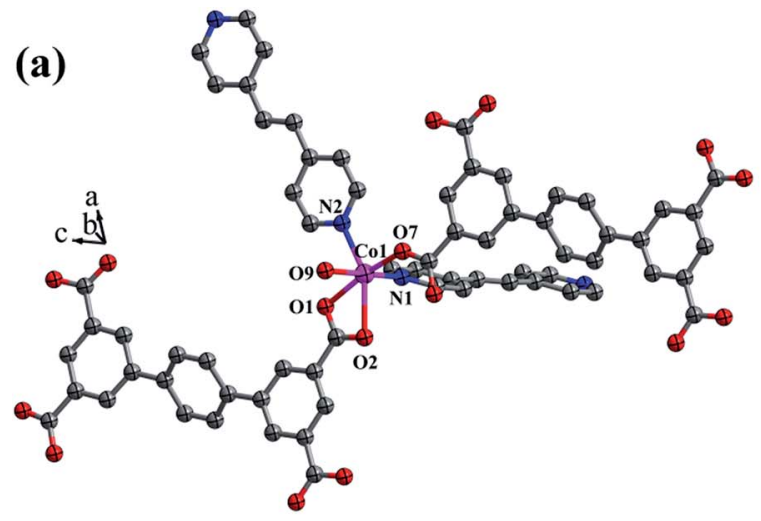

(b)

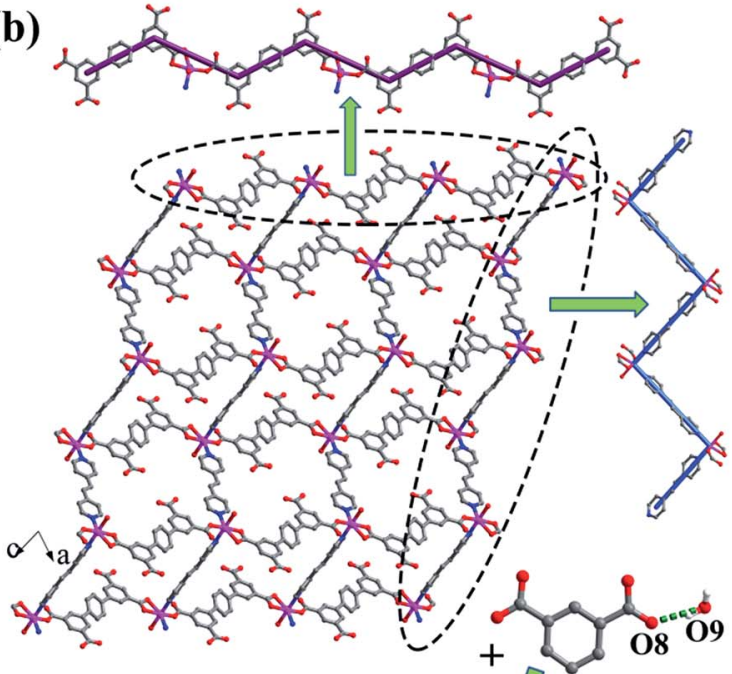

(c)

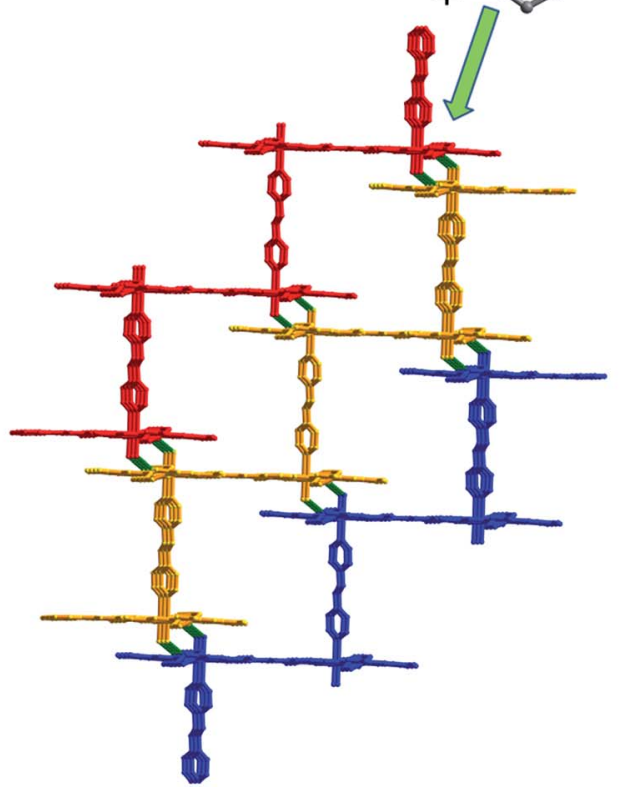

Fig. 7 (a) Coordination environment of the Co" ion in complex 6; (b) 2D layer structure with two types of $1 D$ chain in 6; (c) 3D supramolecular framework formed by hydrogen-bonding interactions in 6 . Color legend: pink, Co; gray, C; blue, N; red, O. All hydrogen atoms from ligands, the lattice $\mathrm{H}_{2} \mathrm{O}$ and $\mathrm{NH}_{4}{ }^{+}$are omitted for clarity.

deprotonated L1 ligands exhibit multiply bidentate and monodentate coordination modes. Complex $\mathbf{1}$ is a 3D $\left\{4^{3} \cdot 6^{3}\right\}_{2}\left\{4^{6} \cdot 6^{6} \cdot 8^{3}\right\}$ framework based on 2D Mn-L1 layers and the 
bridging bpfp ligand, while complex 2 is a $\left\{4^{3}\right\}_{2}\left\{4^{6} \cdot 6^{6} \cdot 8^{3}\right\} 2 \mathrm{D}$ layer constructed from $\mathrm{Mn}^{\mathrm{II}}$ ions, L1 ligands, and the terminal bpe ligands. The reason for the different structures may be that bpfp ligand is more flexible than bpe ligand in the presence of piperazine ring. For complexes $\mathbf{5}$ and $\mathbf{6}$, the fully deprotonated L2 ligands display multiply coordination modes. Complex 5 is a $3 \mathrm{D}\left\{4^{4} \cdot 6^{10} \cdot 8\right\}\left\{4^{4} \cdot 6^{2}\right\}$ net based on a $2 \mathrm{D} \mathrm{Co}-\mathrm{L} 2$ layers and the bridging bpfp ligand, while complex 6 is a $\left\{4^{4} \cdot 6^{2}\right\}$ 2D layer formed with Co-L2 chain and Co-bpe chain. For complexes 3 and $\mathbf{4}$, different transition metal ions coordinate with the partially deprotonated HL1 ligands and bpmp ligands. In complex 3 , a $\left\{4^{4} \cdot 6^{2}\right\} 2 \mathrm{D}$ layer is constructed from $\mathrm{Ni}-\mathrm{HL} 1$ chain and $\mathrm{Ni}-\mathrm{bpmp}$ chain. The $\mathrm{Ni}^{\mathrm{II}}$ metal ion is coordinated with four oxygen atoms and two nitrogen atoms, exhibiting a distorted octahedral coordination configuration. Compared with complex 3, the geometry of $\mathrm{Co}^{\mathrm{II}}$ ions for complex 4 is the same as that of $\mathrm{Ni}^{\mathrm{II}}$ ions. However, the coordination environments of the two crystallographically independent $\mathrm{Co}^{\mathrm{II}}$ ions are different from that of $\mathrm{Ni}^{\mathrm{II}}$ ions. In the final structures, Co-HL1 chain and Co-bpmp chain form a $\{4 \cdot 9 \cdot 10\}\left\{4 \cdot 9^{2}\right\}\left\{4^{2} \cdot 9 \times 10^{3}\right\} 2 \mathrm{D}$ layer.

\section{X-ray powder diffraction}

In order to prove the purities of complexes 1-6, the X-ray powder diffraction (XRPD) patterns have been detected (Fig. S8†). The experimental patterns match the simulated patterns, confirming the phase purities of the samples. The slight differences of intensity between the simulated and experimental peaks may be attributed to the preferred orientation of the crystals.

\section{Thermal stability analysis}

Thermal behaviors of complexes 1-6 were performed by thermogravimetric (TG) analyses (Fig. S9†) in a flowing nitrogen atmosphere between $30{ }^{\circ} \mathrm{C}$ and $800{ }^{\circ} \mathrm{C}$ at a heating rate of $10{ }^{\circ} \mathrm{C}$ $\min ^{-1}$. TGA reveal that complexes 1-6 exhibit two weight loss steps. For complex 1, the weight loss in the first step is $17.20 \%$ between $30^{\circ} \mathrm{C}$ and $127^{\circ} \mathrm{C}$, which is corresponding to the loss of the coordinated water molecules, the lattice water molecules and methanol molecules (calc. $17.87 \%$ ). The second weight loss is $67.86 \%$ between $404{ }^{\circ} \mathrm{C}$ and $563{ }^{\circ} \mathrm{C}$ should be attributed to the release of $\mathrm{H}_{4} \mathrm{~L} 1$ and bpfp ligands (calc. 67.71\%). The possible residual is $\mathrm{MnO}(14.94 \%$, calc. $14.42 \%)$. For complex 2 , the first weight loss is $5.15 \%$ due to the loss of the coordinated water molecules and the lattice water molecules (calc. $4.82 \%$ ). The second weight loss is $75.60 \%$ between $110^{\circ} \mathrm{C}$ and $530{ }^{\circ} \mathrm{C}$, which should be ascribed to the decomposition of $\mathrm{H}_{4} \mathrm{~L} 1$ and bpe ligands (calc. $76.18 \%$ ). The possible residual $\mathrm{MnO}$ is about $19.25 \%$ (calc. $19.00 \%$ ). For complex 3, the weight loss in the first step is $4.75 \%$ between $180{ }^{\circ} \mathrm{C}$ and $295{ }^{\circ} \mathrm{C}$ due to the loss of coordinated water molecules (calc. 4.69\%). The second weight loss is $85.45 \%$ between $295{ }^{\circ} \mathrm{C}$ and $620{ }^{\circ} \mathrm{C}$, which should be attributed to the release of $\mathrm{H}_{4} \mathrm{~L} 1$ and bpfp ligands (calc. $85.58 \%)$. The possible residual is $\mathrm{NiO}(9.80 \%$, calc. $9.73 \%)$. For complex 4 , the first weight loss is $8.30 \%$ between $141{ }^{\circ} \mathrm{C}$ and $178{ }^{\circ} \mathrm{C}$ corresponding to the loss of coordinated water molecule (calc. $8.19 \%$ ). The second weight loss is $74.74 \%$ between $178{ }^{\circ} \mathrm{C}$ and $620{ }^{\circ} \mathrm{C}$ due to the decomposition of $\mathrm{H}_{4} \mathrm{~L} 1$ and bpmp ligands (calc. $74.75 \%$ ). The possible residual CoO is about $16.96 \%$ (calc. $17.06 \%$ ). For complex 5, the weight loss in the first step is $10.70 \%$ in the temperature range of $150-190{ }^{\circ} \mathrm{C}$, which is attributed to the loss of the coordinated water molecules and the lattice water molecules (calc. $11.68 \%$ ). The second weight loss of $73.24 \%$ between $430{ }^{\circ} \mathrm{C}$ and $650{ }^{\circ} \mathrm{C}$ should be ascribed to the release of $\mathrm{H}_{4} \mathrm{~L} 2$ and bpfp ligands (calc. $72.11 \%$ ). The possible residual is $\mathrm{CoO}(16.06 \%$, calc. $16.21 \%)$. For complex 6 , a weight loss of $10.35 \%$ between $125^{\circ} \mathrm{C}$ and $155^{\circ} \mathrm{C}$ is due to the loss of the coordinated water molecules, the lattice water molecules and $\mathrm{NH}_{4}{ }^{+}$(calc. 10.07\%). The second weight loss of $79.02 \%$ between $155{ }^{\circ} \mathrm{C}$ and $600{ }^{\circ} \mathrm{C}$ should be attributed to the decomposition of $\mathrm{H}_{4} \mathrm{~L} 2$ and bpe ligands (calc. 79.46\%). The possible residual is $\mathrm{CoO}(10.63 \%$, calc. $10.47 \%)$.

\section{Fluorescence properties}

The solid-state fluorescence properties of complexes 1-6 and the free organic ligands $\left(\mathrm{H}_{4} \mathrm{~L} 1, \mathrm{H}_{4} \mathrm{~L} 2\right.$, bpfp, bpe and bpmp) have been researched at room temperature. The $\mathrm{H}_{4} \mathrm{~L} 1$ and $\mathrm{H}_{4} \mathrm{~L} 2$ ligands show intense emission peaks with maxima at $436 \mathrm{~nm}$ and $431 \mathrm{~nm}$, respectively. The $\mathrm{N}$-donor ligands (bpfp, bpe and
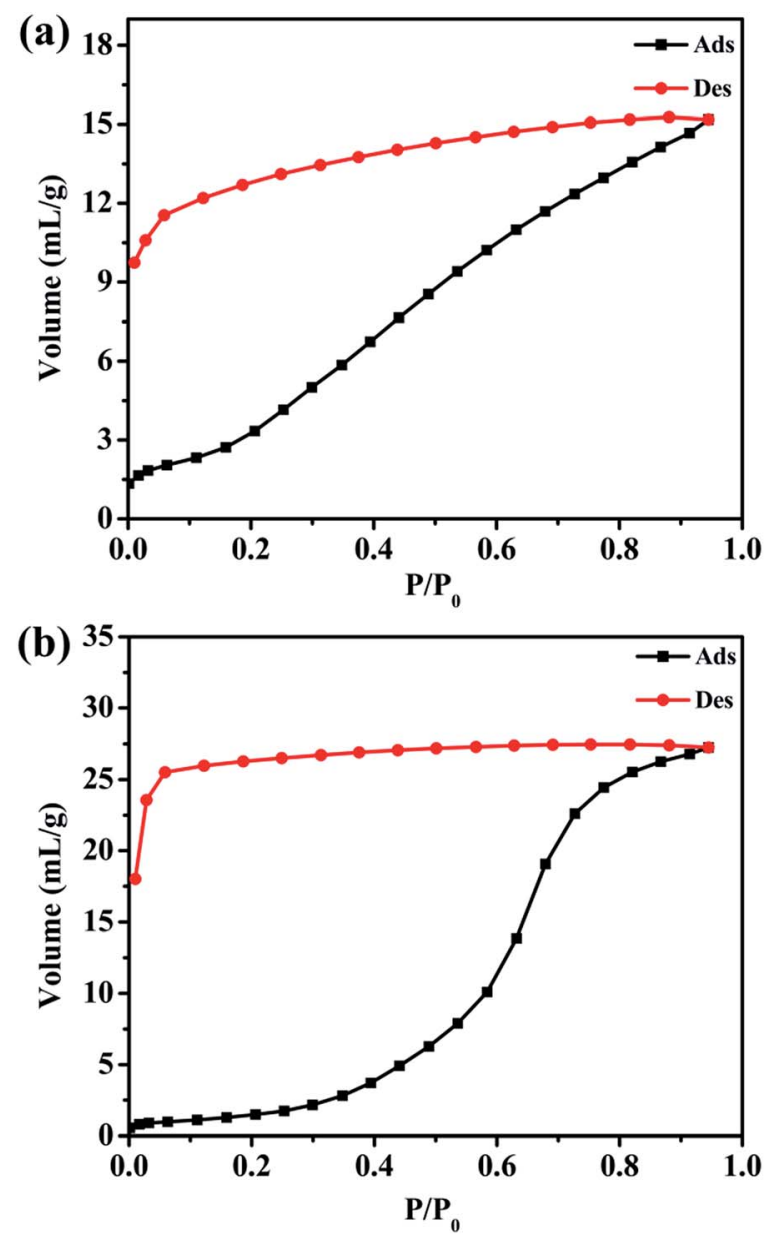

Fig. 8 Water adsorption-desorption isotherms for (a) complex 1; (b) complex 2 at $298 \mathrm{~K}$. 
bpmp) exhibit no significant fluorescent emission (Fig. S10†). Complexes 1-6 display no obvious fluorescence emission, which may be ascribed to $\mathrm{d}-\mathrm{d}$ electron transitions and vibrations of single electrons in $\mathrm{Mn}, \mathrm{Ni}$ or Co complexes. ${ }^{21}$

\section{Water vapor sorption of complexes 1 and 2}

Since there are many interstitial water and methanol molecules in complexes $\mathbf{1}$ and 2, we tried to investigate the sorption properties and the reversibility of the sorption properties. The TGA studies indicate that the solvent molecules could be removed by heating the samples above $130{ }^{\circ} \mathrm{C}$. Therefore, we measured the water vapor sorption behaviour of complexes 1 and 2. Before the measurements, the samples of complexes 1 and 2 were heated at $130{ }^{\circ} \mathrm{C}$ for $12 \mathrm{~h}$ under vacuum to remove the guest molecules. Water vapor sorption isotherms at $298 \mathrm{~K}$ are presented in Fig. 8. Complexes 1 and 2 display the increasing uptake of water, reaching a maximum value of 15.17 $\mathrm{mL} \mathrm{g}^{-1}$ and $27.24 \mathrm{~mL} \mathrm{~g}^{-1}$ at $P / P_{0}=0.95\left(P_{0}\right.$ is the saturation pressure of $\mathrm{H}_{2} \mathrm{O}$ at $298 \mathrm{~K}$ ), respectively. The reason of the obvious hysteresis for desorption isotherms may be the strong adsorption for the water molecules in the pores of these complexes due to the hydrogen bonding interactions in the structure.

\section{Conclusions}

In summary, six coordination polymers based on the main ligands $\quad\left[1,1^{\prime}: 4^{\prime}, 1^{\prime \prime}\right.$-terphenyl $]-2,2^{\prime \prime}, 5,5^{\prime \prime}$-tetracarboxylic acid $\left(\mathrm{H}_{4} \mathrm{~L} 1\right), \quad\left[1,1^{\prime}: 4^{\prime}, 1^{\prime \prime}\right.$-terphenyl $]-3,3^{\prime \prime}, 5,5^{\prime \prime}$-tetracarboxylic acid $\left(\mathrm{H}_{4} \mathrm{~L} 2\right)$ and three types of auxiliary bis-pyridyl ligand have been synthesized under hydrothermal conditions. The different flexibilities of the bis-pyridyl ligands have great influences on the architectural diversity of complexes 1-6. Complexes 1 and 2 exhibit a certain water vapor uptake. This work evidently indicates that the effect of auxiliary ligands and coordination modes of $\mathrm{H}_{4} \mathrm{~L} 1$ and $\mathrm{H}_{4} \mathrm{~L} 2$ are conclusive in the construction of coordination polymers.

\section{Acknowledgements}

This work was supported by the National Nature Science Foundation of China (No. 21271024 and 20971014) and the 111 Project (B07012) in China.

\section{Notes and references}

1 (a) M. Hirscher, Angew. Chem., Int. Ed., 2011, 50, 581; (b) J. R. Li and H. C. Zhou, Nature, 2010, 2, 893; (c) H. L. Jiang and Q. Xu, Chem. Commun., 2011, 47, 3351; (d) R. B. Getman, Y. S. Bae, C. E. Wilmer and R. Q. Snurr, Chem. Rev., 2012, 112, 703; (e) Z. Y. Guo, H. Wu, G. Srinivas, Y. M. Zhou, S. C. Xiang, Z. X. Chen, Y. T. Yang, W. Zhou, M. O'Keeffe and B. L. Chen, Angew. Chem., Int. Ed., 2011, 50, 3178.

2 (a) Z. Y. Guo, J. B. Yu, G. H. Li, Z. J. Si, H. D Guo and H. J. Zhang, CrystEngComm, 2009, 11, 2254; (b) M. H. Zeng,
Q. X. Wang, Y. X. Tan, S. Hu, H. X. Zhao, L. S. Long and M. Kurmoo, J. Am. Chem. Soc., 2010, 132, 2561; (c) X. Zhao, X. H. Bu, Q. G. Zhai, H. Tran and P. Y. Feng, J. Am. Chem. Soc., 2015, 137, 1396; (d) F. Sun, Z. Yin, Q. Q. Wang, D. Sun, M. H. Zeng and M. Kurmoo, Angew. Chem., Int. Ed., 2013, 52, 4538.

3 (a) R. Vaidhyanathan, S. S. Iremonger, G. K. H. Shimizu, P. G. Boyd, S. Alavi and T. K. Woo, Science, 2010, 330, 650; (b) A. Z. Yin, Q. X. Wang and M. H. Zeng, J. Am. Chem. Soc., 2012, 134, 4857; (c) H. Furukawa, N. Ko, Y. B. Go, N. Aratani, S. B. Choi, E. Choi, A. O. Yazaydin, R. Q. Snurr, M. O'Keeffe, J. Kim and O. M. Yaghi, Science, 2010, 329, 424. 4 (a) G. H. Chen, Z. J. Zhang, S. C. Xiang and B. L. Chen, CrystEngComm, 2013, 15, 5232; (b) J. R. Li, J. Sculley and H. C. Zhou, Chem. Rev., 2012, 112, 869; (c) Y. J. Cui, Y. F. Yue, G. D. Qian and B. Chen, Chem. Rev., 2012, 112, 1126; (d) L. J. Dong, W. Chu, Q. L. Zhu and R. D. Huang, Cryst. Growth Des., 2011, 1, 93; (e) C. A. Kent, D. Liu, T. J. Meyer and W. Lin, J. Am. Chem. Soc., 2012, 134, 3991.

5 (a) N. B. Shustova, B. D. McCarthy and M. Dinca, J. Am. Chem. Soc., 2011, 133, 20126; (b) C. B. He, K. D. Lu and W. B. Lin, J. Am. Chem. Soc., 2014, 136, 12253.

6 (a) G. L. Zhuang, L. Tan, W. L. Chen, J. Q. Bai, X. Zhong and J. G. Wang, CrystEngComm, 2014, 16, 6963; (b) L. E. Kreno, K. Leong, O. K. Farha, M. Allendorf, R. P. Van Duyne and J. T. Hupp, Chem. Rev., 2012, 112, 1105; (c) Z. Y. Guo, H. Xu, S. Q. Su, J. F. Cai, S. Dang, S. C. Xiang, G. D. Qian, H. J. Zhang, M. O'Keeffe and B. L. Chen, Chem. Commun., 2011, 47, 5551; (d) Z. C. Hu, B. J. Deibert and J. Li, Chem. Soc. Rev., 2014, 43, 5815.

7 (a) L. Ma, C. Abney and W. Lin, Chem. Soc. Rev., 2009, 38, 1248; (b) H. C. Zhou and S. Kitagawa, Chem. Soc. Rev., 2014, 43, 5415; (c) A. Karmakar, L. M. D. R. S. Martins, S. Hazra, M. F. C. G. D. Silva and A. J. L. Pombeiro, Cryst. Growth Des., 2016, 16, 1837; (d) W. Y. Gao, Y. Chen, Y. H. Niu, K. Williams, L. Cash, P. J. Perez, L. Wojtas, J. F. Cai, Y. S. Chen and S. Q. Ma, Angew. Chem., Int. Ed., 2014, 53, 2615.

8 (a) X. Y. Cao, L. Li, C. X. Li, L. Lv and R. D. Huang, CrystEngComm, 2014, 16, 5093; (b) M. Kurmoo, Chem. Soc. Rev., 2009, 38, 1353; (c) M. H. Zeng, Z. Yin, Y. X. Tan, W. X. Zhang, Y. P. He and M. Kurmoo, J. Am. Chem. Soc., 2014, 136, 4680; (d) L. J. Dong, X. F. Li, J. Cao, W. Chu and R. D. Huang, Dalton Trans., 2012, 42, 1342.

9 (a) J. C. Jin, J. Wu, G. P. Yang, Y. L. Wu and Y. Y. Wang, Chem. Commun., 2016, 52, 8475; (b) N. Stock and S. Biswas, Chem. Rev., 2012, 112, 933; (c) J. C. Jiang, H. Furukawa, Y. B. Zhang and O. M. Yaghi, J. Am. Chem. Soc., 2016, 138, 10244.

10 (a) Z. J. Zhang, H. T. H. Nguyen, S. A. Miller, A. M. Ploskonka, J. B. DeCoste and S. M. Cohen, J. Am. Chem. Soc., 2016, 138, 920; (b) D. M. Chen, J. Y. Tian and C. S. Liu, Inorg. Chem., 2016, 55, 8892; (c) S. Ganguly, S. Mukherjee and P. Dastidar, Cryst. Growth Des., 2016, 16, 5247.

11 (a) D. Wu, J. J. Gassensmith, D. Gouvêa, S. Ushakov, J. F. Stoddart and A. Navrotsky, J. Am. Chem. Soc., 2013, 
135, 6790; (b) F. Gross, E. Sherman, S. L. Mahoney and J. J. Vajo, J. Phys. Chem. A, 2013, 117, 3771; (c) T. Ishiwata, Y. Furukawa, K. Sugikawa, K. Kokado and K. Sada, J. Am. Chem. Soc., 2013, 135, 5427; (d) V. Guillerm, L. J. Weseliński, Y. Belmabkhout, A. J. Cairns, V. D'Elia, L. Wojtas, K. Adil and M. Eddaoudi, Nat. Chem., 2014, 6, 673. 12 (a) J. Canivet, S. Aguado, Y. Schuurman and D. Farrusseng, J. Am. Chem. Soc., 2013, 135, 4195; (b) X. Zhou, P. Liu, W. H. Huang, M. Kang, Y. Y. Wang and Q. Z. Shi, CrystEngComm, 2013, 15, 8125; (c) Y. Q. Lan, H. L. Jiang, S. L. Li and Q. Xu, Inorg. Chem., 2012, 51, 7484; (d) H. J. Li, B. Zhao, R. Ding, Y. Y. Jia, H. W. Hou and Y. T. Fan, Cryst. Growth Des., 2012, 12, 4170.

13 (a) N. Chen, M. X. Li, P. Yang, X. He, M. Shao and S. R. Zhu, Cryst. Growth Des., 2013, 13, 2650; (b) Q. G. Zhai, X. H. Bu, C. Y. Mao, X. Zhao and P. Y. Feng, J. Am. Chem. Soc., 2016, 138, 2524.

14 (a) X. J. Gao, M. X. Zheng, L. Qin, K. Shen and H. G. Zheng, Cryst. Growth Des., 2016, 16, 4711; (b) N. C. Thacker, Z. K. Lin, T. Zhang, J. C. Gilhula, C. W. Abney and W. B. Lin, J. Am. Chem. Soc., 2016, 138, 3501; (c) W. D. Fan, H. Lin, X. Yuan, F. N. Dai, Z. Y. Xiao, L. L. Zhang, L. W. Luo and R. M. Wang, Inorg. Chem., 2016, 55, 6420.
15 S. Kitagawa, R. Kitaura and S. Noro, Angew. Chem., Int. Ed., 2004, 43, 2334.

16 (a) B. B. Kang, N. Wei and Z. B. Han, $R S C A d v .$, 2015, 5, 1605; (b) Y. L. Gai, F. L. Jiang, L. Chen, Y. Bu, K. Z. Su, S. A. AlThabaiti and M. C. Hong, Inorg. Chem., 2013, 52, 7658; (c) Y. L. Wu, G. P. Yang, X. Zhou, J. Li, Y. Ning and Y. Y. Wang, Dalton Trans., 2015, 44, 10385; (d) Y. L. Wu, G. P. Yang, Y. Q. Zhao, W. P. Wu, B. Liu and Y. Y. Wang, Dalton Trans., 2015, 44, 3271.

17 (a) L. L. Zhang, F. L. Liu, Y. Guo, X. P. Wang, J. Guo, Y. H. Wei, Z. Chen and D. F. Sun, Cryst. Growth Des., 2012, 12, 6215; (b) H. Y. Zang, Y. Q. Lan, G. S. Yang, X. L. Wang, K. Z. Shao, G. J. Xu and Z. M. Su, CrystEngComm, 2010, 12, 434; (c) C. Pettinari, N. Masciocchi, L. Pandolfo and D. Pucci, Chem.-Eur. J., 2010, 16, 1106.

18 G. M. Sheldrick, Acta Crystallogr., Sect. A: Found. Crystallogr., 2008, 64, 112.

19 B. Mu and R. D. Huang, CrystEngComm, 2016, 18, 986.

20 X. T. Zhang, L. M. Fan, X. Zhao, D. Sun, D. C. Li and J. M. Dou, CrystEngComm, 2012, 14, 2053.

21 H. Y. Li, L. H. Cao, Y. L. Wei, H. Xu and S. Q. Zang, CrystEngComm, 2015, 17, 6297. 